\title{
Nenačrtno širjenje mestnih območij in megadogodki: gospodarska rast in nedavno širjenje mesta, ki izgublja svojo konkurenčnost (Atene)
}

V sodobnih mestih se lokalna tekmovalnost za finančne vire krepi bolj kot kdaj koli in vodi v razvoj mest, za katera je značilna pomembna družbenoekonomska preobrazba. $V$ dosedanjih raziskavah so avtorji tesno povezavo med širjenjem mest, družbenoekonomskim razvojem in megadogodki proučevali samo za določena območja in vrste rasti mest, pri čemer so pogosto prezrli vlogo megadogodkov pri krepitvi nenačrtnega širjenja mestnih območij. Atene so kot gostiteljica poletnih olimpijskih iger leta 2004 tipičen primer razvijajočega se mesta, ki gosti megadogodek, in sicer predvsem zaradi tesne povezave med olimpijado, razvojem infrastrukture in nenacrrtnim širjenjem mesta. V članku avtorja prikrito razmerje med gospodarskim razmahom kot posledico olimpijskih iger in preveliko liberalnostjo urbanizma povežeta $\mathrm{z}$ dolgo- ročnim nenadzorovanim širjenjem mestnih površin, značilnim za razvoj Aten. Ker so posledične družbenoekonomske razmere omogočile začetni val nenadzorovanega širjenja mestnega območja, jih pojasnjujeta kot šibkost konkurenčnega mesta na slabo načrtovanih in dolgotrajno dereguliranih urbanih območjih, kot je atensko. Podrobna analiza najnovejših razvojnih stopenj gospodarske rasti in nesklenjenega širjenja mestnih površin daje dodaten vpogled $\mathrm{v}$ procese nenačrtnega širjenja današnjih mest in pomaga prepoznati morfološke vzorce in družbenoekonomske dinamike, ki so značilne za širjenje mest med izmenjujočimi se cikli gospodarske rasti in recesije.

Ključne besede: širjenje mest, gospodarska rast, infrastruktura, ekonomije aglomeracij, turizem, Sredozemlje 


\section{Uvod}

Rast mest je globalni pojav, ki se izraža z različnimi prostorskimi oblikami in dinamikami (Angel idr., 2011). Procesi družbenoekonomskega prestrukturiranja in posledična razporeditev gospodarskih dejavnosti po svetu kažejo, da so možnosti za rast mest vse bolj odvisne od njihovih konkurenčnih prednosti pri privabljanju naložb in zagotavljanju lokalnih razvojnih priložnosti (Bennet in Savani, 2003). Glavni dejavniki, ki določajo konkurenčnost mest, so infrastruktura in dostopnost, industrija in obseg gospodarstva ter človeški kapital in delovna sila (Andersen idr., 2011). Politika, katere cilj je povečati sposobnost mest, da privlačijo podjetja in delovno silo, vpliva na oblikovanje regionalne in lokalne politike v razvitih državah (OECD, 2006).

V teh novih globalnih konkurenčnih razmerah in dobi množične komunikacije se je pomen megadogodkov, kot so olimpijske igre, svetovne razstave in svetovna nogometna prvenstva, močno povečal (Chorianopoulos idr., 2010). Potencial, ki ga danes lahko izkoristi gostitelj pomembnega megadogodka, je predvsem svetovna pozornost, namenjena državi in mestu $\mathrm{v}$ tem času ter njuni promociji (Delladetsima, 2006). Megadogodki so torej način privabljanja finančnih naložb z vsega sveta. Konkurenčnost med mesti, ki se potegujejo za organizacijo tovrstnih dogodkov, se je močno povečala (Phelps idr., 2006). Mesta se temeljito spreminjajo in spodbujajo intenziven razvoj infrastrukture, mestno prenovo in razvoj teritorialnih posebnosti, pri čemer je glavni cilj povečanje zmožnosti za rast kraja (Scott, 2001). Na kratko, mesta se spreminjajo hitreje zato, da bi postala konkurenčnejša in bi lahko gostila megadogodke.

Premik k modelu konkurenčnega mesta je razviden iz dveh regulatornih odzivov, katerih cilj je spremeniti konkurenčne značilnosti urbanih sistemov (Kresl, 2007). Pri prvem gre za ukrepe, ki so usmerjeni $k$ povpraševanju in $s$ katerimi zagotovimo tiste pozitivne značilnosti, ki jih podjetja zahtevajo od neke lokacije, da lahko tam poslujejo. Ključen primer tovrstnega odziva je gradnja fizične infrastrukture, zaradi katere postane območje privlačnejše za naložbe in ugodnejše za vzpostavitev in rast lokalnih gospodarskih pobud. Pri drugem regulatornem odzivu pa gre za strategije razvoja ali izboljšanja podobe kraja, pri katerih s poudarjanjem njegovih glavnih prednosti in kulturnih značilnosti dosežemo, da izstopa od drugih naložbenih možnosti. Za spodbujanje prenove mestne podobe se uporabljajo različna politična orodja in viri, vključno z ohranjanjem območij arhitekturne dediščine, gradnjo pomembnih gradbenih objektov, ki spreminjajo podobo mestnega središča, in gostitvijo pomembnih kulturnih, podjetniških in športnih dogodkov. V tem pogledu zdaj trženje kraja velja za bistveni del načrtovanja rabe zemljiščc, ki usmerja razvoj krajev (Bennet in Savani, 2003).

Z novimi podjetniškimi mesti se lokalna tekmovalnost za finančne vire krepi bolj kot kdaj koli in vodi v nastanek konkurenčnih mest, za katera sta značilni morfološka in funkcionalna preobrazba (Di Feliciantonio in Salvati, 2015). V tem pogledu so megadogodki pomemben način samopromocije, zaradi česar se pred njimi vedno gradi nova infrastruktura in izvajajo strategije za izboljšanje podobe mesta, ki gosti dogodek (Longhi in Musolesi, 2007). Kljub temu so raziskovalci v preteklosti tesno povezavo med megadogodki, družbenoekonomskim razvojem in širjenjem mest proučevali samo za neka območja in vrste rasti mest, pri čemer so pogosto prezrli vlogo megadogodkov pri krepitvi razpršene urbanizacije in posledičnem nastanku negativnih družbeno-okoljskih zunanjih učinkov (Dura-Guimera, 2003). Zaradi tesne povezave med megadogodkom, razvojem infrastrukture in nenačrtnim širjenjem mestnega območja v družbenoekonomskih razmerah, za katere je značilno dolgotrajno nenadzorovano širjenje mestnih površin, je mesto Atene kot gostitelj olimpijkkih iger leta 2004 primer tipičnega olimpijskega mesta (Chorianopoulos idr., 2014).

Kandidatura Aten za organizacijo olimpijskih iger je bila videti kot želja po povrnitvi konkurenčnosti mesta (Gargiulo Morelli idr., 2014). Ko je bila Grčija izbrana za gostiteljico, se je začelo izvajati več urbanističnih in infrastrukturnih projektov, ki naj bi ublažili gospodarsko obrobnost prestolnice in izboljšali njeno funkcionalnost (Gospodini, 2006). Olimpijske igre so spodbudile preusmeritev prostorske politike $\mathrm{k}$ izboljšanju atenske mestne krajine (Beriatos in Gospodini, 2004), hkrati pa je širjenje mestnih površin pred začetkom svetovne gospodarske krize vodilo v netrajnostni lokalni razvoj, kar je najverjetneje zmanjšalo (ali celo ogrozilo) sposobnost metropolitanskega sistema, da se učinkovito odzove na poznejše negativne vplive recesije (Gospodini, 2009). Na podlagi tega avtorja $\mathrm{v}$ članku proučujeta prikrito povezavo med gospodarskim razmahom kot posledico olimpijskih iger in preveliko liberalnostjo urbanizma ter ugotavljata, da je pri tem šlo za močan proces nenačrtnega širjenja mesta, ki ga obravnavata kot zgodnji znak šibkosti konkurenčnega mesta na slabo načrtovanih in dolgotrajno dereguliranih urbanih območjih (Salvati idr., 2016). Podrobna analiza najnovejših razvojnih stopenj gospodarske rasti in nesklenjenega širjenja mestnih površin daje dodaten vpogled $\mathrm{v}$ vzorce in procese nenačrtnega šijenja današnjih mest in pomaga prepoznati morfološke vzorce in družbenoekonomske dinamike, ki so značilne za urbanizacijo $\mathrm{v}$ izmenjujočih se ciklih gospodarske rasti in recesije.

Po kratkem opisu dolgotrajnega demografskega in urbanega razvoja atenske metropolitanske regije (drugo poglavje) 


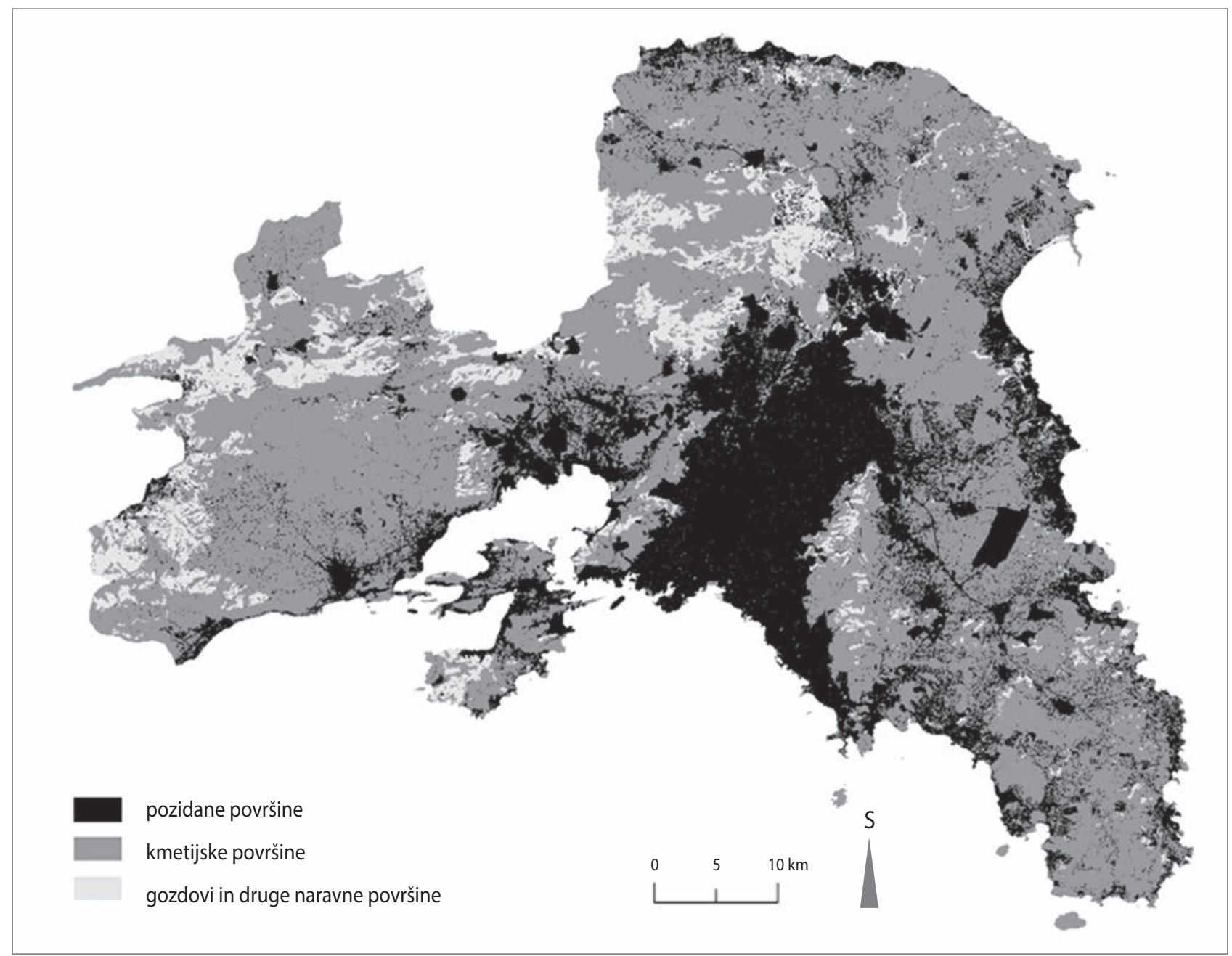

Slika 1: Prostorska razporeditev osnovnih kategorij rabe zemljišč v atenski metropolitanski regiji (vir: Evropska agencija za okolje, 2012)

avtorja na podlagi pregleda empiričnih ugotovitev drugih raziskav predstavita štiri homogena obdobja širjenja mesta. $\mathrm{V}$ tretjem poglavju se na podlagi pregleda novejše literature o rasti in širjenju mestnih površin $\mathrm{v}$ grški prestolnici ter dodatne analize gradiva, kot so mestni načrti, strateške smernice urbanega razvoja in spletni časopisni članki, osredotočita na razvoj Aten v zadnjem desetletju in na vlogo olimpijskih iger leta 2004. Posledice tovrstnih svetovnih dogodkov v sodobnih konkurenčnih mestih obravnavata v četrtem poglavju, kjer proučujeta, kakšno preobrazba se dogaja v mestih, da bi ta povečala svojo svetovno konkurenčnost. Urbanistično politiko in strategije, ki so jih grške oblasti sprejele pred olimpijado in takoj po njej, na kratko predstavita $\mathrm{v}$ petem poglavju. $\mathrm{V}$ šestem poglavju nato proučujeta prostorske posledice zadevnih urbanističnih načrtov, pri čemer posebno pozornost posvetita preobrazbi Mezogejske ravnine, ki je eno izmed območij, na katero se Atene najbolj širijo. Za to uporabita statistične podatke grškega državnega statističnega urada in diahrone letalske posnetke programa Google Earth.

\section{2 Širjenje Aten: dolgotrajna urbanizacija}

Proučevano območje obsega upravno območje Atika v osrednjem delu južne Grčije. Atika pokriva samo 3 \% grškega ozemlja, vendar je v njej ustvarjena skoraj polovica grškega BDP (slika 1). Leta 2001 je $\mathrm{v}$ širši atiški regiji živelo približno 3,5 milijona ljudi oziroma 34 \% celotnega grškega prebivalstva (Salvati, 2016). Atene so grška prestolnica in daleč najpomembnejše mesto $\mathrm{v}$ državi, $\mathrm{v}$ katerem so skoncentrirana vsa gospodarska področja in dejavnosti (najvišje ravni javne uprave, sedeži podjetij in najrazličnejše storitve). $\mathrm{V}$ evropskem urbanem sistemu pa Atene ne zasedajo visokega mesta, saj po raznih klasifikacijah evropskih mest veljajo za obrobno mesto $\mathrm{z}$ razmeroma majhnim vplivom na Sredozemlje in širšo Evropo (Rontos idr., 2016).

Kostas Rontos in Luca Salvati (2014) sta določila štiri obdobja rasti v Atenah. V prvem, ki je trajalo od leta 1850 do leta 1900, 
se je število prebivalcev na mestnih in podeželskih območjih večalo v podobnem obsegu in je bilo prebivalstvo precej enakomerno razporejeno po regiji. $\mathrm{Na}$ začetku šestdesetih let 19. stoletja so Atene začele rasti hitreje kot druga območja v Atiki. V drugem obdobju (1900-1940) se je razvila strnjena policentrična oblika, ki temelji na dveh glavnih mestnih središčih - Atenah in Pireju (Leontidou, 1990).

Širše območje Aten je utrdilo svojo vlogo grške prestolnice, $s$ čimer je postalo privlačnejše za industrializacijo, še zlasti v Pireju, kjer je komercialno pristanišče. Posledično je bila stopnja rasti prebivalstva na teh dveh območjih izjemno visoka, predvsem zaradi priseljevanja iz Male Azije. Prišleki so se naselili v nenačrtovana predmestja v okolici Aten in Pireja. Ob tem ko neformalna naselja niso bila ravno redko pozidana, so se v tem obdobju že kazali prvi znaki nenačrtnega širjenja mesta. Tretje obdobje (1950-1980) je zaznamovala postopna preobrazba tradicionalne dvosrediščne zgradbe Atike. Delavci, predstavniki nižjih slojev in podeželski priseljenci so se preselili v okolico Aten in Pireja v iskanju cenovno dostopnih stanovanj v bližini tovarn. Posledično so se razlike v gostoti poselitve mestnih središč in obrobij hitro zmanjševale, poleg tega pa se je v tem obdobju tudi urbaniziralo podeželje v okolici Aten in Pireja, še zlasti Mezogejske ravnine. Zmanjšanje razlik mestnih območij je bilo mogoče predvsem zaradi infrastrukturnega razvoja regije, ugodne urbanistične politike in ohlapnih gradbenih predpisov (Leontidou, 1996).

Razpršena urbanizacija se je okrepila v četrtem obdobju (19801990), ko se je močno povečalo odseljevanje srednjega razreda in najvišjega sloja iz mesta. Za obrobje Aten, tj. podeželska in obalna območja je bil v teh letih značilen hiter razmah gospodarstva, za urbano območje Aten pa sta bila značilna rast in nenačrrno širjenje mestnih površin. Končna ugotovitev glede demografskega in urbanega razvoja te regije je, da so se tradicionalne razlike med mestom in podeželjem $\mathrm{v} 20$. stoletju temeljito spremenile. Strnjeno policentrično zgradbo Atike, ki je temeljila na dvojici Atene-Pirej, čedalje bolj nadomešča bolj razpršena metropolitanska zgradba (Sayas, 2004, 2006; Polyzos idr., 2008; Salvati, 2013).

\section{Tekmovanje za organizacijo megadogodkov: zgodnji znaki konkurenčnega mesta v Atenah}

Atensko metropolitansko območje je s približno tretjino celotnega grškega prebivalstva in več kot tretjino vseh ustvarjenih prihodkov v državi najpomembnejše območje v grškem urbanem sistemu. Kljub temu je bil kazalnik konkurenčnosti za Atene mnogo desetletij med najnižjimi v Evropi, kar je bila posledica različnih dejavnikov, povezanih z vase zaprto gospodarsko usmeritvijo mesta ter njegovimi dolgotrajnimi socialnimi težavami in zastarelo infrastrukturo (Prevelakis, 2000). Olimpijada je bila zato priložnost, da se grška prestolnica svetu pokaže $\mathrm{v}$ novi podobi zmagovalke in $\mathrm{mu}$ (po besedah organizatorjev) dokaže, da ima poleg veličastne preteklosti tudi obetavno prihodnost. $S$ tega vidika je bilo pri organizaciji iger bolj v ospredju nacionalno kot lokalno prizadevanje (Beriatos in Gospodini, 2004). Centralna vlada je k temu cilju usmerila regionalno politiko in dodelila precejšnja sredstva za izvedbo projektov, $s$ katerimi naj bi se izboljšala konkurenčnost mesta (Chorianopoulos idr., 2010).

Na podlagi tega sta nastali dve glavni vrsti projektov. Prva je vključevala projekte, $s$ katerimi bi se izboljšali privlačnost mestnega okolja in sposobnost mesta, da deluje kot mednarodno prizorišče celoletnega turizma (na primer projekt združitve arheoloških najdišč v starem mestnem jedru, projekt obnove zahodnega obrežja in projekt preureditve športnih objektov v konferenčne, poslovne in zabaviščne prostore po olimpijadi). Druga vrsta pa je obsegala projekte, s katerimi naj bi ublažili gospodarsko obrobnost in izboljšali funkcionalne vidike metropolitanskega območja, zlasti na področju telekomunikacij in prometne infrastrukture (na primer projekt atenske podzemne železnice z novima progama 2 in 3 ter razširitvijo proge 1, projekt povezave mestnega središča $\mathrm{z}$ zahodnim obrežjem $s$ predmestno železniško in tramvajsko progo, odprtje mednarodnega letališča Eleftherios Venizelos in gradnja atenske obvoznice).

Olimpijske igre so torej spodbudile preusmeritev prostorske politike v spodbujanje konkurenčnosti mesta (Gospodini, 2006). Namesto razpravljanja o obsegu gospodarske rasti mesta in države se bomo v tem prispevku raje osredotočili na vplive tovrstne politike na urbani razvoj proučevanega območja. Pri usmerjanju urbanega razvoja v tej regiji sta ključno vlogo imela dva glavna vidika: (a) pojav novih prostorskih povezav na podlagi gradnje pomembnih prometnih projektov, ki so vzpostavili nove povezave med obrobnimi območji, razširili funkcionalne meje mesta in preoblikovali podobo metropole, ter (b) spremembe $\mathrm{v}$ dinamiki nepremičnin, povezane $\mathrm{z}$ visoko stopnjo naložb $\mathrm{v}$ infrastrukturo in pomembnimi arhitekturnimi deli (Panagiotis in Tassos, 2004). Prvi vidik je pomagal povečati privlačnost podeželja v okolici mesta (nova infrastruktura je bila v glavnem zgrajena na Mezogejski ravnini ter vzdolž vzhodne in zahodne obale), drugi pa je vplival na oblikovanje kulturnih in prostočasnih središč, za katera sta značilni inovativna oblika ter posebna arhitekturna in urbana morfologija, ki ima bolj mednarodni kot lokalni pridih (Beriatos in Gospodini, 2004). Pojav združenj investitorjev, ki se osredotočajo na priložnosti za naložbe $\mathrm{v}$ gradnjo velikih trgovskih središč, poslovnih prostorov, zabaviščnih objektov 
in stanovanjskih naselij, čedalje bolj vpliva na ceno zemljišč, kar otežuje razvoj (Delladetsima, 2006). Infrastruktura se je gradila na različnih lokacijah $\mathrm{v}$ Atenah, večina naložb pa je bila usmerjena v vzhodni del metropole: na Mezogejsko ravnino (Couch idr., 2007).

\section{Razvoj infrastrukture in širjenje mestnih površin v Atenah}

Širjenje mesta, povezano z življenjskim slogom, in širjenje mesta, ki ga spodbuja razvoj infrastrukture, sta glavna dejavnika, ki vplivata na razpršeno gradnjo v mestih (Richardson in Chang-Hee, 2004; Bruegmann, 2005; Salvati in Carlucci, 2016). Proučevanje razvoja infrastrukture na območju Atike je uporabno za razumevanje prejšnjih vzorcev širjenja mest in napovedovanje prihodnjih. Infrastruktura, ki najpomembneje določa naravo in značilnosti procesov nenačrtnega širjenja mestnega območja, vključuje letalǐ̌ča, ceste in podzemno železnico (Zagorianakos, 2004). Z gradnjo prve podzemne železnice (proge 1) na širšem območju Aten, uradno odprte leta 1869, je bilo središče Pireja povezano s središčem Aten. Šlo je za enega izmed prvih podzemnih železniških sistemov na svetu. Pozneje, leta 1957, so začeli progo 1 pospešeno podalǰ̌evati, tako da je danes dolga $20 \mathrm{~km}$ in poteka od jugozahodnega dela širšega območja Aten (Pireja) do njegovega severovzhodnega dela (Kifisie).

Leta 1992 je upravljanje atenske podzemne železnice prevzelo podjetje Attiko Metro in začelo graditi progi 2 in 3 ter dodatno podališevati progo 1 . Skupen strošek teh gradbenih del je bil približno 4,3 milijarde evrov. Današnja atenska podzemna železnica je dolga več kot $60 \mathrm{~km}$, v gradnji pa je še ena (četrta) proga. Celoten sistem javnega prevoza v Atenah je bil sčasoma preoblikovan, da bi pokrival čim več območij v Atenski kotlini. Javni prevoz prinaša številne koristi: hitrost, udobje, varnost in zanesljivost. $Z$ gradnjo proge 4 in načrtovanimi razširitvami prog 2 in 3 bodo obrobna območja na severovzhodu in jugu širše atenske regije povezana $s$ središčem mesta, posredni učinek vsega navedenega pa je tudi krepitev nesklenjenega mestnega tkiva, še zlasti v severovzhodnih okrožjih širšega območja Aten. Poleg tega je smiselno napovedati, da se bo nenadzorovano širjenje mestnih površin na teh območjih neizogibno okrepilo, saj bodo zaradi zgrajene infrastrukture postala bolj zaželena.

Avtocesta A6 (v gršcini znana kot Attiki Odos) je sodobna avtocesta, dolga $65 \mathrm{~km}$, ki tvori obvoznico atenskega metropolitanskega območja. Je najpomembnejši del cestnega omrežja atiške regije, ki povezuje mednarodno letališče Eleftherios Venizelos v Spati s Korintom in Patrasom. Glavni namen njene gradnje je bil zmanjšati promet $\mathrm{v}$ prestolnici in Atenski kotlini ter spodbuditi razvoj fizičnega in urbanističnega načrtovanja $\mathrm{v}$ atiških prefekturah. Avtocesta A6 tako ključno vpliva na urbani razvoj na obrobju širšega območja Aten in drugod po Atiki, poleg tega sta tudi prostorsko nesklenjen razvoj (ang. leapfrog sprawl) in trakasto oziroma linearno širjenje poselitve vzdolž prometnih poti (ang. ribbon sprawl) v zadnjem desetletju posledica predvsem gradnje te avtoceste. Tudi njeno načrtovano podaljšanje na Mezogejski ravnini (s čimer bi to območje prek gorovja Himet povezali s širšim območjem Aten) bo verjetno pomembno vplivalo na razpršeno urbanizacijo te ravnine (Chorianopoulos idr., 2014).

\section{Kandidatura za organizacijo olimpijskih iger in priložnost Aten, da postanejo konkurenčne: posledice $z$ vidika nenačrtnega širjenja mesta}

Megadogodki so izvrstna priložnost za prenovo urbanega okolja mest, vendar če pri tem niso sprejete ustrezne načrtovalske strategije, lahko tudi negativno vplivajo na kakovost življenja $\mathrm{v}$ mestu, ki gosti dogodek. Kot v številnih drugih mestih je bil tudi v Atenah uspeh strateškega načrta mestnega razvoja morebiten vzrok težav, ki so se pojavile zaradi prevrednotenja nekaterih mestnih območij. Kot navaja Francisco-Javier Monclùs (2003), so pospešene težnje po decentralizaciji razvoja in eksponentno povečanje mobilnosti na metropolitanskem območju povezani s precejšnjimi energijskimi stroški, večjo rabo zemljišč in daljšim časom vsakodnevne vožnje na delo. V nasprotju z uspešnimi mednarodnimi izkušnjami številnih mest, ki so organizacijo megadogodkov izkoristila za prenovo obsežnih območij v središču mesta, se Atene niso odločile za takšno strategijo (Petsimeris, 2008). Čeprav je bilo dovolj primernih lokacij na nekdanjih industrijskih območjih v središču mesta (na primer v predelu Eleonas v atenski občini), se projekti za olimpijado leta 2004 niso osredotočali na to območje, ampak so bili razpršeni po vsej Atiki.

Kot ugotavljata Elias Beriatos in Aspasia Gospodini (2004), ta vzorec nakazuje strategijo, ki spodbuja policentrično mestno prenovo in razvoj. Poleg tega načrtovalcem z več kulturnimi in prostočasnimi središči, ki so bila zgrajena v okviru olimpijskih iger in v katere je bilo vloženih ogromno javnih sredstev, ni uspelo oblikovati nove kulturne in prostočasne četrti v mestni krajini, saj so bili ti projekti razpršeni po vsej Atiki (slika 2). Večina atletskih kompleksov je bila dopolnjena z drugimi objekti, kot so konferenčne in razstavne dvorane, trgovine, objekti, namenjeni razvedrilu, parki in sprehajališča, kar naj bi izboljšalo kakovost mestnega prostora. $S$ tega vidika tvorijo 


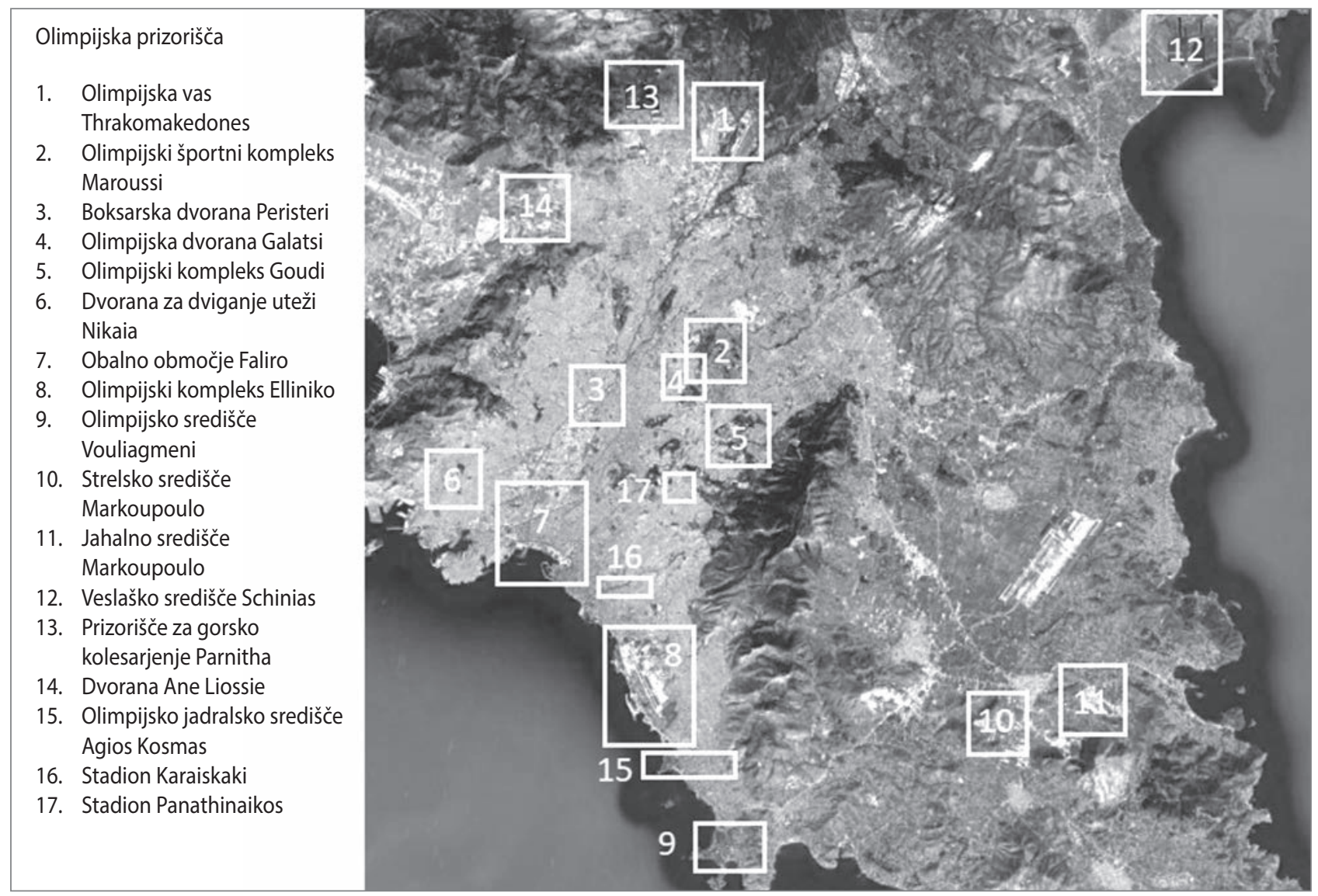

Slika 2: Olimpijski objekti na širšem območju Aten; prizorišči št. 10 in 11 sta na Mezogejski ravnini (vir: Google Earth, 2010)

Preglednica 1: Odstotni deleži sprememb vrednosti zemljišč glede na območje in referenčno obdobje (vir: Grški nacionalni statistični urad, 2014)

\begin{tabular}{lllll}
\hline Območje & Sprememba $(\mathrm{v} \%)$ & \multicolumn{2}{l}{ Razlika v primerjavi z Atenami } \\
\hline Grčija & $1997-2000$ & $2004-2009$ & 2004 & 2009 \\
\hline Atika & 51,9 & 17,7 & 0,7 & 0,8 \\
\hline Prefektura Atene & 40,6 & 10,5 & 1,0 & 1,0 \\
\hline Prefektura Vzhodna Atika & 122,7 & 7,8 & 1,0 & 0,9 \\
\hline Prefektura Zahodna Atika & 23,5 & 20,9 & 0,8 & 0,6 \\
\hline Prefektura Pirej & 8,3 & 5,5 & 0,6 & 0,8 \\
\hline
\end{tabular}

gruče kulturnih in prostočasnih dejavnosti (Gospodini, 2001), ki so razpršene po vseh atiških metropolitanskih okrožjih (v središču mesta, na njegovem obrobju in v predmestjih).

$\mathrm{V}$ preglednici 1 so prikazani odstotni deleži sprememb vrednosti zemljišč $\mathrm{v}$ dveh izbranih obdobjih (1997-2000 in 2004-2009) na ravni Grčije, Atike in štirih atiških prefektur (Aten, Pireja ter Zahodne in Vzhodne Atike). Vrednosti zemljišč so se v obeh obdobjih povečale na vseh proučevanih območjih. Porast je bil največji v obdobju 1997-2000, in sicer na vseh območjih, razen v prefekturi Pirej, ki je med vsemi območji verjetno še najbolj strnjeno. Poleg tega je treba poudariti, da se je vrednost zemljišč $\mathrm{v}$ obeh obdobjih najbolj enakomerno večala v prefekturi Vzhodna Atika (oziroma Mezogejskem okrožju), kjer je bila urbanizacija v zadnjih desetletjih najmočnejša. Najbolj zanimive rezultate dobimo, če spremembe vrednosti zemljišč obravnavamo kot absolutni odklon od podatkov za atensko prefekturo, ki je že od nekdaj najdražje območje v državi. Te spremembe so se na vseh proučevanih območjih močno povečale med letoma 2004 in 2009, razen v prefekturi Zahodna Atika, kjer so vrednosti ostale skoraj enake v celotnem obdobju. Na podlagi tega lahko sklepamo, da vrednosti zemljišč po vsej Atiki sčasoma postajajo enotnejše. Povpraševanje po zemljiščih zunaj atenske prefekture se je postopoma večalo po urbanizaciji in razvoju infrastrukture tudi drugje po Atiki (Panagiotis in Tassos, 2004).

Prostorsko nesklenjen razvoj in linearno širjenje poselitve vzdolž prometnih poti sta močno spodbudila razpršenost olimpijskih prizorišč po vsej regiji, ki je posledica razvoja 

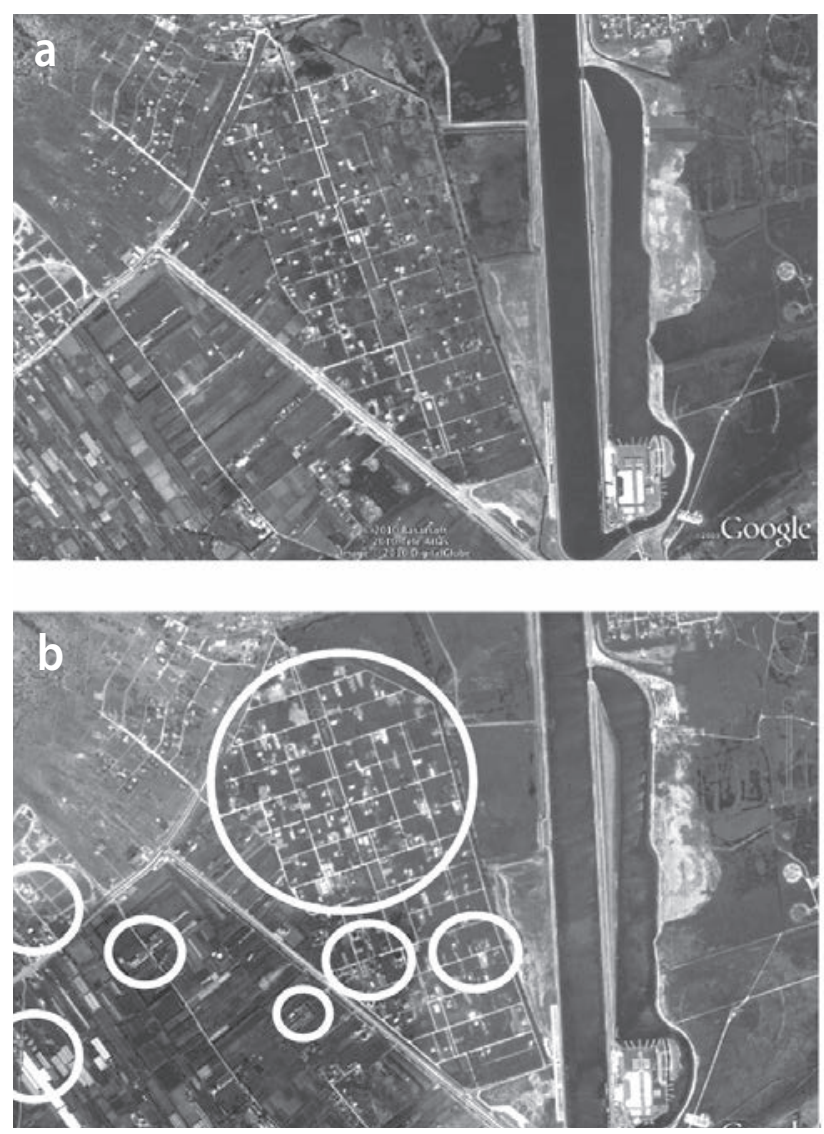

Slika 3: Širjenje mesta v bližini olimpijskega veslaškega središča Schinias: (a) aprila 2004 in (b) junija 2010; za prostorsko nesklenjen razvoj so značilna izolirana naselja in majhna urbana jedra, ki se širijo na podeželje, za trakasto ali linearno širjenje mestnega območja pa je značilna poselitev vzdolž cest in drugih infrastrukturnih omrežij (vir: Google Earth, 2012)

prometnega sektorja, zlasti na Mezogejski ravnini. Zaradi tovrstnega nenačrtnega širjenja mestnega območja, ki so ga posredno spodbujali novozgrajeni športni objekti, se je v Atiki oblikovala policentrična prostorska zgradba, pri čemer se je po okrožjih razvila gručasta pozidava, ki je sledila precej liberalnemu programu prostorskega razvoja, kar je bilo v nasprotju $s$ strateškim glavnim načrtom mesta (slika 3). Razvoj policentrične ozemeljske zgradbe je še zlasti značilen za Mezogejsko ravnino, obsežno območje vzhodno od atenskega somestja. Gora Himet na zahodu deluje kot fizična pregrada, ki ločuje ravnino od glavnega somestja. Preobrazba Mezogejske ravnine se je začela v osemdesetih letih 20. stoletja, ko je bila sprejeta odločitev o preselitvi mednarodnega mestnega letališca na to območje. Razlastitvi kmetijskih zemljišč za gradnjo letališča so sledile nadaljnje naložbe v infrastrukturo, ki so jih omogočala sredstva, dodeljena za organizacijo olimpijskih iger. Nove ceste in železniške proge, ki so letališče povezale z mestom, so močno izboljšale dostopnost območja. Vse skupaj je zaokrožila gradnja dveh pomembnih olimpijskih prizorišč (jahalnega in strelskega središča blizu kraja Markopoulo), tudi ti dve sta nastali na razlaščenih kmetijskih zemljiščih.
Širjenje mestnih površin na Mezogejski ravnini ni bilo načrtovano, nanj pa je močno vplival infrastrukturni razvoj tega območja. Zaradi koncentracije industrijskih dejavnosti, pomembnih naložb v prometno infrastrukturo, ki je to območje povezala s preostalo Atiko, in razmeroma nizkih stroškov zemljišč je Mezogejska ravnina postala zelo ugodna za gradnjo in rast predmestij (Chorianopoulos idr., 2014). Posledično se je število tamkajšnjih prebivalcev v osemdesetih letih 20. stoletja povečalo za 26.207, v devetdesetih letih 20. stoletja pa za 38.737. Število gospodinjstev na Mezogejski ravnini se je od leta 1981 do leta 2001 povečalo s 15.800 na 37.117 (+135\%), povprečna velikost gospodinjstev pa se je s 3,3 osebe zmanjšala na 1,3 osebe. $V$ istem obdobju se je število prebivalcev na širšem območju Aten zmanjševalo, na okoliških območjih pa povečevalo (Couch idr., 2007).

Da bi določile družbenoekonomske posledice tovrstnih naložb v infrastrukturo, so oblasti v zgodnjih devetdesetih letih 20. stoletja naročile izdelavo podrobne prostorskonačrtovalske študije Mezogejske ravnine. Na podlagi te študije so bili oblikovani novi predpisi za rabo tal na tem območju, vključno $z$ omejitvami parcelacij in gradnje, ki pa so začele veljati šele leta 2003, torej leto pred začetkom olimpijskih iger in skoraj dve desetletji po sprejetju glavnega strateškega načrta za Atene (Giannakourou, 2005). V tem obdobju je bil obseg nove mestne rabe tal na območju obsežnih infrastrukturnih projektov $15 \%$ celotne rabe tal na Mezogejski ravnini. Več kot $50 \%$ novih mestnih zemljišč oziroma zemljišč z mestno rabo tal je bilo na zavarovanih območjih (zelenih površinah ali kmetijskih zemljiščih). Tovrstna območja so zavzemala do 10 \% vseh zemljišč na Mezogejski ravnini in zanje je bil značilen največji porast mestne rabe tal. Poleg tega so se razširila pozidana zemljišča tako na starih kot novih industrijskih območjih, kar kaže na porast proizvodnih dejavnosti na tem območju. Manj kot $15 \%$ novih mestnih zemljišč je bilo na območjih, ki so jih urejali strukturni urbanistični načrti. Za ta območja je bil značilen tudi najnižji porast mestne rabe tal med vsemi načrtovalskimi območji na Mezogejski ravnini (Chorianopoulos idr., 2010).

\section{Posledice konkurenčnega mesta: olimpijski val nenačrtnega širjenja mestnih površin v Atenah}

Atene so tipičen primer sredozemskega mesta, $\mathrm{v}$ katerem je urbani razvoj dolgo potekal večinoma nenačrtno in spontano (Carlucci idr., 2017). Ker gre za tipičen primer južnoevropskega urbanega območja z zmerno rastjo prebivalstva in čezmerno urbanizacijo, razrast Aten ponazarja zapleteno razmerje med megadogodki in nenačrtnim širjenjem mestnega 
območja (Ioannidis idr., 2009). Na podlagi obsežne literature o procesih nenačrtnega širjenja mestnih površin na tem območju pred olimpijado (Leontidou, 1996; Maloutas, 2007; Arapoglou in Sayas, 2009; Chorianopoulos idr., 2014) je v tem članku predstavljen pregled načinov in dinamik tovrstnega širjenja v primeru Atike, pri čemer avtorja na podlagi družbenoekonomskih dinamik na lokalni ravni izločita štiri procese, značilne za olimpijsko obdobje širjenja mesta: (a) prostorsko nesklenjen razvoj, (b) industrijski razvoj na metropolitanskem obrobju, (c) trakasti ali linearni razvoj in (d) preobrazbo počitniških domov v glavna bivališča.

Razvidni so številni primeri prostorsko nesklenjenega šijenja mesta na območja zunaj somestja, ki pa še vedno niso predaleč za vsakodnevno vožnjo na delo. Po vsej Atiki lahko najdemo primere širjenja mestnih površin na obstoječe vasi zunaj mesta, okoli zelenih vasi in vzdolž obalnih mestec, to širjenje pa je lahko povezano tudi z zakonodajo, ki ureja načrtovanje ukrepov. Prostorsko nesklenjeno širjenje mesta je bilo običajno povezano z gradnjo velikih objektov ali industrijskih območij, zato so tudi olimpijske igre leta $2004 \mathrm{z}$ vsemi deli, povezanimi $s$ tem megadogodkom, močno okrepile tovrstno nenačrtno širjenje mesta. Gradnja olimpijske vasi je bila na primer še en primer nesklenjenega širjenja mesta na še nepozidana zemljišča, ki se zdaj spreminja v oddaljen, a prestižen stanovanjski kompleks za delavce. Druge skupine prebivalcev pa so se zaradi različnih razlogov selile $\mathrm{v}$ bližino glavnih olimpijskih objektov in drugam na obrobje Aten (Emmanuel, 2004).

Z vidika regionalnega industrijskega razvoja so se prve tovarne na obrobju Aten pojavile na meji med Atiko in Beocijo. Ta predmestna industrijska rast je najprej potekala spontano v obliki gručaste pozidave blizu glavnih prometnih žil (Kourliouros, 1997), temu pa je sledilo priseljevanje delavcev na primestna industrijska območja na Mezogejski ravnini in zunaj Atike (vzdolž državne avtoceste med Atenami in Lamio na severu ter med Atenami in Korintom na jugozahodu). Zaradi soobstoja podeželske in mestne ter stanovanjske, industrijske in trgovske rabe tal so nastale mešane krajine. Tovrstno nenačrtno širjenje mesta je morfološko podobno trakastemu, vendar sta tukaj obravnavana ločeno, ker imata različne vzroke.

Če se osredotočimo na trakasto obliko nenačrtnega širjenja mesta in robna mesta, so urbanizacijo kmetijskih zemljišč v prvih povojnih desetletjih urejali gradbeni predpisi v okviru sprejetih mestnih načrtov, ki so dovoljevali razvoj več vrst mestne rabe prostora (stanovanjsko, industrijsko in trgovsko rabo) vzdolž prometnih osi, zaradi česar se je tam razvila trakasta oblika urbanizacije (Economou, 1997). Gre za obliko nenačrtnega širjenja mesta, ki ga spodbuja razvoj infrastrukture in pri kateri imajo ključno vlogo prometne poti. Zaradi čedalje večje uporabe avtomobilov so se hiše dobro prodajale tudi, če so bile oddaljene od trgovin in drugih storitev. Glavni dejavniki, ki so spodbudili tovrstno širjenje mesta, so vključevali razne urbane dejavnosti na obrobju mesta, ki so zavzemale obsežna zemljišča in so bile odvisne od prometnih povezav (na primer podružnice tovarn, skladišča, razstavišča in hipermarketi). Tovrstnega prostorskega razvoja niso urejali predpisi namenske rabe prostora ali kateri koli drugi predpisi, ki bi nadzirali rabo prostora, zaradi česar so se oblikovali predeli, kjer so prevladovale podobne dejavnosti, ki so bile močno odvisne od prometnih sistemov (Coccossis idr., 2005). Tovrsten urbani razvoj je povzročil postopno opuščanje tradicionalne strnjene pozidave, značilne za sredozemska mesta (Economidou, 1993).

Posebna oblika trakastega prostorskega razvoja je bila mogoča, ko sta bili vzhodna in zahodna atiška obala povezani z mestom. Številni pripadniki atenskega srednjega sloja so imeli na mestnem obrobju blizu obale $\mathrm{v}$ lasti počitniške domove, kjer so lahko v prostem času uživali v mirnih kotičkih ob morju (Sayas, 2006). Z razvojem prometne infrastrukture so ta območja postala lažje dostopna tudi iz mestnega središča, kar je omogočilo dnevno vožnjo na delo (Couch idr., 2007). Tako so se središča na mestnem obrobju iz poletnih lokacij spremenila v glavna bivališča pripadnikov srednjega in višjega sloja. Z nadaljnjim združevanjem Evrope in zlasti po sprejetju Maastrichtske pogodbe so se bogatejši prebivalci sezonsko selili iz mest in $\mathrm{v}$ tujino, tovrstno sezonsko preseljevanje pa se je precej okrepilo s prihodom nizkocenovnih letalskih družb, zaradi katerih si je potovanje lahko privoščilo več ljudi.

Posledično je sredozemske obale zajel val rezidenčnega turizma, pri katerem so se ljudje sezonsko selili s severa na jug, kar je povzročilo nekakšno nenačrtno širjenje mest na dolge razdalje. Poleg Španije in Italije velja Grčija za najbolj priljubljeno sredozemsko destinacijo med sezonskimi migranti. Olimpijske igre v Atenah leta 2004 so močno spodbudile turizem v državi, nemški, britanski in avstrijski državljani pa so začeli kupovati hiše na obalah Atike. Skoraj 30 \% vseh novih hiš na tem območju so kupili tujci, mednarodni vlagatelji pa napovedujejo, da bo v bližnji prihodnosti povpraševanje po najmanj milijonu hiš za turiste (Couch idr., 2007).

\section{Razprava}

Za boljše razumevanje družbenoekonomske dinamike in morfoloških značilnosti najnovejšega vala nenačrtnega širjenja mest pri urbanizaciji Sredozemlja sta se avtorja v raziskavi osredotočila na primer tovrstnega širjenja v olimpijskih Atenah, kjer so olimpijske igre leta 2004 ključno vplivale na dinamiko tega širjenja na tem območju. Razlogov za podrobno analizo najnovejšega razvoja Aten kot tipičnega primera sredozemskega mesta, ki privablja več prebivalcev kot je delovnih mest, je več (Allen idr., 2004). Urbani razrast Aten na splošno 
velja za tipičen primer novejših smeri družbenoekonomskega razvoja južnoevropskih mest, za katera je značilna preobrazba iz strnjene pozidave v nenačrrno širjenje mestnega območja, pri katerem gre lahko tudi za policentrični prostorski razvoj ( $\mathrm{Tu}$ rok in Mychnenko, 2007). Do devetdesetih let 20. stoletja so bile Atene strnjeno mesto, danes pa pozornost raziskovalcev vzbuja postopen premik mesta $\mathrm{k}$ nenačrtnemu prostorskemu širjenju. Proučevanje razlogov in vzrokov za prehod iz strnjene pozidave $v$ trenutni proces nenadzorovane prostorske širitve je pomembno za boljše razumevanje prihodnjih urbanih vzorcev v Sredozemlju in drugje po Evropi.

Druga tipična lastnost sredozemskih mest, ki je še zlasti dobro vidna v primeru Aten, je nenačrtna oblika njihovega širjenja (Vaiou, 1997). V večini sredozemskih mest urbanizacija ne temelji na zakonih, ki urejajo rabo zemljišč in poselitev, kot je to značilno za druga evropska mesta. Poleg tega so Atene eno redkih večjih urbanih območij v Evropi, na katerem je število prebivalstva vsaj do leta 2010 intenzivno naraščalo, čemur je sledil močan proces čezmerne urbanizacije, ki je preoblikoval značilno podeželsko krajino okoli mesta (Weber idr., 2005). Zaradi tega to območje bolj kot kdaj koli prej zahteva podrobno prostorsko analizo, na podlagi katere bi lahko uvedli ustrezne strategije za nadzor razpršene urbanizacije, ki je v zadnjem času še zlasti intenzivna (Kasanko idr., 2006; Schneider in Woodcock, 2008; Salvati, 2014).

Atene so tudi dober primer za proučevanje pomena megadogodkov v novem kontekstu mestnih regij. Grčija je z olimpijskimi igrami vzbudila pozornost svetovne javnosti, poleg tega pa so zaradi tega megadogodka Atene postale dober primer za preučevanje tega, kako nova konkurenčna dinamika mesta vpliva na procese urbanizacije (Gospodini, 2009). Dela, ki so bila izvedena za ta megadogodek v Atiki, so povzročila dve glavni posledici: pojav novih prostorskih povezav (vključno $\mathrm{z}$ razširitvijo funkcionalnih mej mesta) in spremembe v dinamiki nepremičnin (dvig vrednosti zemljišč na podeželju in mestnem obrobju). Tovrstni posegi so bili razpršeni po vseh Atenah, na podlagi česar se je oblikoval nekakšen program policentrične urbane prenove (Gospodini, 2006). To je spodbudilo trakast in prostorsko nesklenjen urbani razvoj, ki je povzročil proces nenadzorovanega širjenja mesta, ki je najbolj viden na Mezogejkki ravnini, torej na nekdanjem kmetijskem območju. Vse skupaj je omogočilo povečano mestno rabo prostora v okolici tovarn in olimpijkkih prizorišč (na primer strelskega in jahalnega središča), na zavarovanih območjih in vzdolž glavnih prometnih poti. Poleg tega se je na tem območju število prebivalcev močno povečalo, povprečna velikost gospodinjstev pa se je zmanjšala.

Za Atiko je značilna predvsem prostorsko nesklenjena širitev mestnih območij, pri čemer so se okoli olimpijskih prizorišč razvila številna manjša, od mesta ločena središča, ki pa so z mestom povezana s cestami in železnico. Razvile so se tudi druge oblike prostorsko nesklenjenega razvoja, kot so na primer nova naselja, ki so jih okoli industrijskih con zgradile interesne skupine. Druga značilna oblika nenačrtne prostorske širitve na celotnem proučevanem območju je trakasta poselitev oziroma pozidava, ki se pojavlja vzdolž glavnih prometnih osi, kot je na primer avtocesta A6. To kaže na to, da je najnovejša nenačrtna prostorska širitev Aten predvsem posledica razvoja infrastrukture. $\mathrm{Na}$ ta vzorec močno vpliva tudi decentralizacija dejavnosti, ki zavzemajo veliko prostora in so odvisne od prometnih povezav, vključno $s$ tovarnami in trgovskimi središči. Ena izmed oblik trakastega prostorskega razvoja je tudi preobrazba počitniških domov v glavna bivališča. Z boljšimi povezavami med obalo in mestom so se številni predstavniki srednjega razreda, ki so živeli v mestu, odločili svoje sezonske počitniške hiše spremeniti v glavna bivališča. Zaradi tega se je družbenoekonomska podoba nekdanjih počitniških krajev temeljito spremenila in se približala mestni prostorski rabi.

Na splošno velja, da so bile oblike urbanega razvoja Aten v 20. stoletju posledica tako posrednih kot neposrednih dejavnikov, raziskovalci pa so pred tem podobno ugotovili tudi za druga mesta (Arbaci, 2008; Catalàn idr., 2008; Terzi in Bolen, 2009; Bayona-Carrasco in Gil-Alonso, 2012; Litynski, 2016; Salvati in Carlucci, 2016). Zaradi morfoloških lastnosti grškega ozemlja je bila za grški urbani sistem vedno značilna delitev med mesti in podeželjem (Costa idr., 1991), v 20. stoletju pa je kljub vsemu značilna hitra preobrazba tradicionalnega razmerja med mestnimi in podeželskimi območji. Zaradi te preobrazbe, ki so jo spodbujali gospodarski razvoj prestolnice in njene nenavadne razsežnosti, močno priseljevanje, slab načrtovalski sistem z ohlapnimi gradbenimi predpisi in infrastrukturni razvoj območja, se je spremenila prostorska kakovost atiške regije, kar je povzročilo postopno (in nesklenjeno) urbanizacijo okolice širšega območja Aten (Di Feliciantonio in Salvati, 2015). Vse to postopno zmanjšuje razlike med mestom in podeželjem, značilne za sredozemski prostor. Podobno kot pri španskih, portugalskih in italijanskih mestih je tudi gospodarska zgradba Aten v povojnem obdobju hitre urbanizacije temeljila na urbanizacijskih ekonomijah, ki so sprožale posamične primere industrializacije (Carlucci idr., 2017). Mesta zato ni zadel običajni val deindustrializacije in dezurbanizacije, ki je bil od sedemdesetih let 20. stoletja značilen za severnoevropska mesta. Število prebivalcev v mestu se še naprej povečuje v samosvojem življenjskem ciklu (Gargiulo Morelli idr., 2014).

Hkrati v večini sredozemskih mest urbanizacija ni temeljila na zakonodaji, ki ureja rabo zemljišč in mestno poselitev, tako kot je to značilno za druga evropska mesta (Coccossis idr., 2005). Urbani razvoj je večinoma potekal s širjenjem nezakonitih samogradenj na poceni zemljiščih $\mathrm{v}$ predmestjih, kjer ni bilo dovolj primerne infrastrukture (Economou, 1997).Zaradi tega 
so prebivalci teh območij postali socialno izključeni in ranljivi (Emmanuel, 2004). S tega vidika nedavna smer prostorske rasti v Atenah ponazarja obliko individualiziranega urbanega razvoja, saj mesto še naprej raste nenačrtovano in predvsem na podlagi majhnih gradbenih projektov, ki jih lastniki sami financirajo, pri čemer so omejena javna sredstva za gradnjo mestne infrastrukture večinoma odvisna od organizacije občasnih (čeprav pomembnih) dogodkov (Couch idr., 2007).

\section{Sklep}

Družbenoekonomske razmere, na katerih temelji prikrita povezava med gospodarsko rastjo, ki so jo spodbudile olimpijske igre leta 2004, in preveliko liberalnostjo urbanizma, ki je prispevala k nenadzorovanemu širjenju Aten, lahko pojasnimo kot znak šibkosti konkurenčnega mesta na slabo načrtovanem in dolgotrajno dereguliranem urbanem območju. Podrobna analiza nedavnih obdobij gospodarske rasti in nesklenjenega mestnega razvoja daje dodaten vpogled $\mathrm{v}$ kompleksne mehanizme razpršene urbanizacije $\mathrm{v}$ današnjem metropolitanskem območju. Zaradi nove spreminjajoče se ozemeljske zgradbe atiške regije bi bilo treba na novo razmisliti o vlogah metropolitanskih območij. Atika leži na sredini prometnih poti med industrijskim severnim delom države, kmetijskim vzhodom in jugom ter turističnimi Egejskimi otoki. Bi morala biti torej Atika nova prestolnica Grčije? Gre pri tem za preprost proces širjenja mesta na preostali nezaseden prostor ob upoštevanju geografskih ovir ali pa gre mogoče za učinek preseljevanja mestnega prebivalstva in infrastrukture, kar celotno regijo povezuje v kompleksno mrežo ne glede na metropolitansko hierarhijo, prostorsko sklenjenost, funkcionalna proizvodna območja in različno rabo tal? $V$ tem pogledu bo pravila te spreminjajoče se kompleksne sredozemske regije določala nova atiška regija, in ne več samo Atene, pri čemer bo pomembno vlogo imela politika, ki ureja metropolitansko območje. V nasprotju s projekti, zgrajenimi za olimpijske igre, se regionalno načrtovanje ne bi smelo več usmerjati v konkretne posege na redko poseljenih in pozidanih območjih (ki so bili včasih potrebni zaradi izjemnih razmer), s čimer bi se oblikoval program razvoja atenske regije, ki bi bil lahko zgled za prihodnji razvoj več sredozemskih mest, ki doživljajo gospodarsko rast, hkrati pa se spopadajo $s$ propadanjem mestnih središč.

\section{Luca Salvati}

Italian Council for Agricultural Research and Economics (CREA), Rim, Italija

E-naslov: luca.salvati@uniroma1.it

Marco Zitti

Sapienza University of Rome, Rim, Italija

E-naslov: marcozitti@libero.it

\section{Viri in literatura}

Allen, J., Barlow, J., Leal, J., Maloutas, T., in Padovani, L. (2004): Housing in southern Europe. London, Blackwell. DOI: 10.1002/9780470757536

Andersen, H. T., Møller-Jensen, L., in Engelstoft, S. (2011): The end of urbanization? Towards a new urban concept or rethinking urbanization. European Planning Studies, 19(4), str. 595-611.

DOI: 10.1080/09654313.2011.548472

Angel, S., Parent, J., Civco, D. L., Blei, A., in Potere, D. (2011): The dimensions of global urban expansion: Estimates and projections for all countries, 2000-2050. Progress in Planning, 75(2), str. 53-107. DOI: 10.1016/j.progress.2011.04.001

Arapoglou, V. P., in Sayas, J. (2009): New facets of urban segregation in southern Europe. European Urban and Regional Studies, 16(4), str. 345362. DOI: 10.1177/0969776409340187

Arbaci, S. (2008): (Re)viewing ethnic residential segregation in southern European cities: Housing and urban regimes as mechanisms of marginalisation. Housing Studies, 23(4), str. 589-613. DOI: 10.1080/02673030802117050

Bayona-Carrasco, J., in Gil-Alonso, F. (2012): Suburbanisation and international immigration: The case of the Barcelona Metropolitan Region (1998-2009). Tijdschrift voor Economische en Sociale Geographie, 103(3), str. 312-329. DOI: 10.1111/j.1467-9663.2011.00687.x

Bennett, R., in Savani, S. (2003): The rebranding of city places: An international comparative investigation. International Public Management Review, 4(2), str. 70-87.

Beriatos, E., in Gospodini, A. (2004): Glocalising urban landscapes: Athens and the 2004 Olympics. Cities, 21(3), str. 187-202. DOI: 10.1016/j.cities.2004.03.004

Bruegmann, R. (2005): Sprawl: A compact history. Chicago, University of Chicago Press. DOI: 10.7208/chicago/9780226076973.001.0001

Carlucci, M., Grigoriadis, E., Rontos, K., in Salvati, L. (2017): Revisiting a hegemonic concept: Long-term "Mediterranean urbanization" in between city re-polarization and metropolitan decline. Applied Spatial Analysis and Policy, 10(3), str. 347-362. DOI: 10.1007/s12061-016-9186-2

Catalàn, B., Sauri, D., in Serra, P. (2008): Urban sprawl in the Mediterranean? Patterns of growth and change in the Barcelona metropolitan region 1993-2000. Landscape and Urban Planning, 85(3-4), str. 174-184.

Chorianopoulos, I., Pagonis, T., Koukoulas, S., in Drymoniti, S. (2010): Planning, competitiveness and sprawl in the Mediterranean city: The case of Athens. Cities, 27(4), str. 249-259.

DOI: 10.1016/j.cities.2009.12.011

Chorianopoulos, I., Tsilimigkas, G., Koukoulas, S., in Balatsos, T. (2014): The shift to competitiveness and a new phase of sprawl in the Mediterranean city: Enterprises guiding growth in Messoghia - Athens. Cities, 39, str. 133-143. DOI: 10.1016/j.cities.2014.03.005

Coccossis, H., Economou, D., in Petrakos, G. (2005): The ESDP relevance to a distant partner: Greece. European Planning Studies, 13(2), str. 253264. DOI: $10.1080 / 0965431042000321811$

Costa, F. J., Noble, A. G., in Pendeleton, G. (1991): Evolving planning systems in Madrid, Rome, and Athens. Geojournal, 24(3), str. 293-303. DOI: 10.1007/BF00189030

Couch, C., Petschel-Held, G., in Leontidou, L. (2007): Urban sprawl in Europe: Landscapes, land-use change and policy. Oxford, Blackwell. DOI: 10.1002/9780470692066

Delladetsima, P. (2006): The emerging property development pattern in Greece and its impact on spatial development. European Urban and Regional Studies, 13(3), str. 245-278. DOI: 10.1177/0969776406065428 
Di Feliciantonio, C., in Salvati, L. (2015): "Southern" alternatives of urban diffusion: Investigating settlement characteristics and socioeconomic patterns in three Mediterranean regions. Tijdschrift voor Economische en Sociale Geografie, 106(4), str. 453-470. DOI: 10.1111/tesg.12102

Dura-Guimera, A. (2003): Population deconcentration and social restructuring in Barcelona, a European Mediterranean city. Cities, 20(6), str. 387-394. DOI: 10.1016/j.cities.2003.08.004

Economidou, E. (1993): The Attic landscape throughout the centuries and its human degradation. Landscape and Urban Planning, 24(1), str. 33-37. DOI: 10.1016/0169-2046(93)90079-S

Economou, D. (1997): The planning system and rural land use control in Greece: A European perspective. European Planning Studies, 5(4), str. 461-476. DOI: 10.1080/09654319708720412

Emmanuel, D. (2004): Socio-economics inequalities and housing in Athens: Impacts of the monetary revolution of the 1990s. The Greek Review of Social Research, 113(A), str. 121-143. DOI: 10.12681/grsr.9355

Evropska agencija za okolje (2012): CORINE Land Cover geospatial database. Dostopno na: http://land.copernicus.eu/pan-european/corineland-cover/view (sneto 11. 5. 2017).

Gargiulo Morelli, V., Rontos, K., in Salvati, L. (2014): Between suburbanisation and re-urbanisation? Revisiting the urban life cycle in a Mediterranean compact city. Urban Research and Practice, 7(1), str. 74-88. DOI: 10.1080/17535069.2014.885744

Giannakourou, G. (2005): Transforming spatial planning policy in Mediterranean countries. Europeanization and domestic change. European Planning Studies, 13(2), str. 253-264.

DOI: 10.1080/0365431042000321857

Google Earth (2010): Pro images collection. Dostopno na: https://www. google.it/intl/it/earth/ (sneto 11. 5. 2017).

Google Earth (2012): Pro images collection. Dostopno na: https://www. google.it/intl/it/earth/ (sneto 11. 5. 2017).

Gospodini, A. (2001): Urban waterfront redevelopment in Greek cities. Cities, 18(5), str. 285-295. DOI: 10.1016/S0264-2751(01)00022-1

Gospodini, A. (2006): Portraying, classifying and understanding the emerging landscapes in the post-industrial city. Cities, 23(5), str. 311330. DOI: $10.1016 /$ j.cities.2006.06.002

Gospodini, A. (2009): Post-industrial trajectories of Mediterranean European cities: The case of post-Olympics Athens. Urban Studies, 46(5-6), str. 1157-1186. DOI: 10.1177/0042098009103859

Grški nacionalni statistični urad (2014): Population and housing cenzus. Dostopno na: http://www.statistics.gr (sneto 5. 5. 2017).

Ioannidis, C., Psaltis, C., in Potsiou, C. (2009): Towards a strategy for control of suburban informal buildings through automatic change detection. Computers, Environment and Urban Systems, 33(1), str. 64-74. DOI: 10.1016/j.compenvurbsys.2008.09.010

Kasanko, M., Barredo, J. I., Lavalle, C., McCormick, N., Demicheli, L., Sagris, V., idr. (2006): Are European cities becoming dispersed? A comparative analysis of fifteen European urban areas. Landscape and Urban Planning, 77(1-2), str. 111-130. DOI: 10.1016/j.landurbplan.2005.02.003

Kourliouros, E. (1997): Planning industrial location in Greater Athens: The interaction between deindustrialization and anti-industrialism during the 1980s. European Planning Studies, 5(4), str. 435-460. DOI: 10.1080/09654319708720411

Kresl, P. K. (2007): Planning cities for the future. The successes and failures of urban economic strategies in Europe. Cheltenham, VB, Edward Elgar. DOI: $10.4337 / 9781847204332$
Leontidou, L. (1990): The Mediterranean city in transition. Cambridge, Cambridge University Press. DOI: 10.1017/CBO9780511522208

Leontidou, L. (1996): Alternatives to modernism in (southern) urban theory: Exploring in-between spaces. International Journal of Urban and Regional Research, 20(2), str. 180-197. DOI: 10.1111/j.1468-2427.1996. tb00310.x

Litynski, P. (2016): The correlation between urban sprawl and the local economy in Poland. Urbani izziv, 27(2), str. 86-96.

Longhi, C., in Musolesi, A. (2007): European cities in the process of economic integration: Towards structural convergence. Annals of Regional Science, 41(2), str. 333-351. DOI: 10.1007/s00168-006-0104-4

Maloutas, T. (2007): Segregation, social polarization and immigration in Athens during the 1990s: Theoretical expectations and contextual difference. International Journal of Urban and Regional Research, 31(4), str. 733-758. DOI: 10.1111/j.1468-2427.2007.00760.x

Monclùs, F. J. (2003): El “Modelo Barcelona” ¿Una fórmula original? De la "reconstrucción" a los proyectos urbanos estratégicos. Urban Perspectives, 3, str. 1-13.

OECD (Organisation for Economic Co-operation and Development) (2006): Competitive cities in the global economy. Pariz.

Panagiotis, Z., in Tassos, L. (2004): The impact of the Athens 2004 Olympic games on real estate value in Greece. Journal of Property Tax Assessment and Administration, 1(3), str. 5-20.

Petsimeris, P. (2008): Playing with scales: Doxiadis legacy in urban theory and practice. Ekistics, 442, str. 326-352.

Phelps, N. A., Parsons, N., Ballas, D., in Dowling, A. (2006): Post-suburban Europe: Planning and politics at the margins of Europe's capital cities. Basingstoke, VB, Palgrave Macmillan. DOI: 10.1057/9780230625389

Polyzos, S., Christopoulou, O., Minetos, D., in Leal Filho, W. (2008): An overview of urban-rural land use interactions in Greece. International Journal of Agricultural Resources, Governance and Ecology, 7(3), str. 276296. DOI: 10.1504/JJARGE.2008.018330

Prevelakis, G. (2000): Athenes. Urbanism, culture et politique. Pariz, L'Harmattan.

Richardson, H. W., in Chang-Hee, C. B. (2004): Urban sprawl in Western Europe and the United States. London, Ashgate.

Rontos, K., Grigoriadis, S., Sateriano, A., Syrmali, M., Vavouras, I., in Salvati, L. (2016): Lost in protest, found in segregation: Divided cities in the light of the 2015 "Oki" referendum in Greece. City, Culture and Society, 7(3), str. 139-148. DOI: 10.1016/j.ccs.2016.05.006

Rontos, K., in Salvati, L. (2014): Is the ratio of present to resident population a proxy for urban diffusion? A case study. International Journal of Ecological and Economic Statistics, 32(1), str. 75-82.

Salvati, L. (2013): Exploring the spatial pattern of soil sealing in a Mediterranean peri-urban area. Journal of Environmental Planning and Management, 57(6), str. 848-861. DOI: 10.1080/09640568.2013.770730

Salvati, L. (2014): Towards a polycentric region? The socioeconomic trajectory of Rome, an "ethernal" Mediterranean city. Tijdschrift voor Economische en Sociale Geografie, 105(3), str. 268-284. DOI: $10.1111 /$ tesg. 12054

Salvati, L. (2016): The dark side of the crisis: Disparities in per-capita income (2000-2012) and the urban-rural gradient in Greece. Tijdschrift voor Economische en Sociale Geografie, 107(5), str. 628-641. DOI: $10.1111 /$ tesg. 12203

Salvati, L., in Carlucci, M. (2016): Patterns of sprawl: The socioeconomic and territorial profile of dispersed urban areas in Italy. Regional Studies, 50(8), str. 1346-1359. DOI: 10.1080/00343404.2015.1009435 
Salvati, L., Sateriano, A., in Grigoriadis, S. (2016): Crisis and the city: Profiling urban growth under economic expansion and stagnation. Letters in Spatial and Resource Science, 9(3), str. 329-342.

DOI: 10.1007/s12076-015-0160-4

Sayas, J. P. (2004): An exploration of the social and spatial division of labour in the Athenian urban space. The Greek Review of Social Research, 113, str. 167-206. DOI: 10.12681/grsr.9357

Sayas, J. P. (2006): Urban sprawl in the periurban coastal zones of Athens. The Greek Review of Social Research, 120(B), str. 71-104.

Schneider, A., in Woodcock, C. E. (2008): Compact, dispersed, fragmented, extensive? A comparison of urban growth in 25 global cities using remotely sensed data, pattern metrics and census information. Urban Studies, 45(3), str. 659-692. DOI: 10.1177/0042098007087340

Scott, A. J. (2001): Global city-regions. Trends, theory, policy. Oxford, Oxford University Press.

Terzi, F., in Bolen, F. (2009): Urban sprawl measurement of Istanbul. European Planning Studies, 17(10), str. 1559-1570.

DOI: 10.1080/09654310903141797

Turok, I., in Mykhnenko, V. (2007): The trajectories of European cities, 1960-2005. Cities, 24(3), str. 165-182. DOI: 10.1016/j.cities.2007.01.007

Vaiou, D. (1997): Facets of spatial development and planning in Greece. European Planning Studies, 5(4), str. 431-433.

DOI: 10.1080/09654319708720410

Weber, C., Petropoulou, C., in Hirsch, J. (2005): Urban development in the Athens metropolitan area using remote sensing data with supervised analysis and GIS. International Journal of Remote Sensing, 26(4), str. 785-796. DOI: 10.1080/01431160512331316856

Zagorianakos, E. (2004): Athens 2004 Olympic Games' transportation plan: A missed opportunity for strategic environmental assessment (SEA) integration. Journal of Transport Geography, 12(2), str. 115125. DOI: 10.1016/j.jtrangeo.2003.12.001 